\title{
Spontaneous Regression of Extruded Lumbar Disc Herniation: Three Cases Report
}

\author{
Sung Gon Kim, Joo Chul Yang, Tae Wan Kim, Kwan Ho Park \\ Department of Neurosurgery, VHS Medical Center, Seoul, Republic of Korea
}

Herniated nucleus pulposus (HNP) is a common disease that induces back pain and radicular pain. Some cases require surgical treatment due to persistent severe pain. However, in some cases, pain can be relieved with conservative treatment or at times relived spontaneously. Therefore, the most effective treatment method for HNP is undefinable. Spontaneous regression of HNP has been recognized with the advancement of radiological diagnostic tools and can explain the reason of spontaneous relief of symptoms without treatment.

Key Words: Herniated disc $\cdot$ Extrusion $\cdot$ Spontaneous regression

\section{INTRODUCTION}

Herniated nucleus pulposus (HNP) is a common disease that induces back pain and radicular pain. The pathogenesis of radicular pain is not clearly defined. Inflammation of the nerve root and intervertebral disc tissue may be a major factor to radiculopthy. Some cases require surgical treatment due to persistent severe pain. However, in most cases, pain can be relieved with conservative treatment or in some, spontaneously. Spontaneous regression of HNP is thought to occur via an inflammatory reaction with macrophages and molecular mechanisms of phagocytic processes ${ }^{4,5,6}$. The reaction generated by meninges may also lead to spontaneous regression even in the intradural HNP case ${ }^{3)}$. Even in patients with large disc herniation, spontaneous regression of disc is a possible condition $^{10,12,13,15)}$. Therefore, non-surgical treatment can be an another therapeutic option to treat large HNP, if there is no neurological deficit, ${ }^{7,12,13,14)}$.

The authors report three cases of spontaneous regression of lumbar extruded disc with disappearance of symptom.

\footnotetext{
- Received: April 22, 2013 • Revised: May 26, 2013

- Accepted: May 29, 2013

Corresponding Author: Tae Wan Kim, MD

Department of Neurosurgery, VHS Medical Center, 53 Jinhwangdo-ro,

61-gil, Gangdong-gu, Seoul 134-791, Republic of Korea

Tel: +82-2-2225-1363, Fax: +82-2-2225-4152

E-mail: euro3399@naver.com
}

\section{CASE REPORT}

\section{Case 1}

A 64-year-old male was admitted to our hospital with radiating pain and numbness in the right lower extremity. The symptom was aggravated one week ago. The motor weakness and sensory change was not noted. Magnetic resonance (MR) images showed extruded herniated nucleus pulposus (HNP) at the L 3-4 level (Fig. 1A, B). He refused surgical treatment, so we performed transforaminal neural block. The symptom was relieved and he was discharged. On subsequent follow up, the symptom appeared to be gradually relieved. Follow-up MR study was done 3 months after and showed no HNP (Fig. 1C, D). He did not complain of any symptom at that time.

\section{Case 2}

A 74-year-old male was admitted to our emergency room with pain that aggravated a day ago on the right anterior thigh and buttock. He had undertaken discectomy at the L 4-5 level 2 years ago. MR images showed ruptured HNP at the L 1-2 level (Fig. 2A, B). He did not have motor weakness and bladder symptom. We started pain control by intravenous analgesics and muscle relaxant. Pain was subsided and he wanted to be discharged with oral medication. Three months later, he was admitted to our hospital for a follow-up checkup with no symptom. Ruptured HNP was not noted on MR image (Fig. 2C, D). 

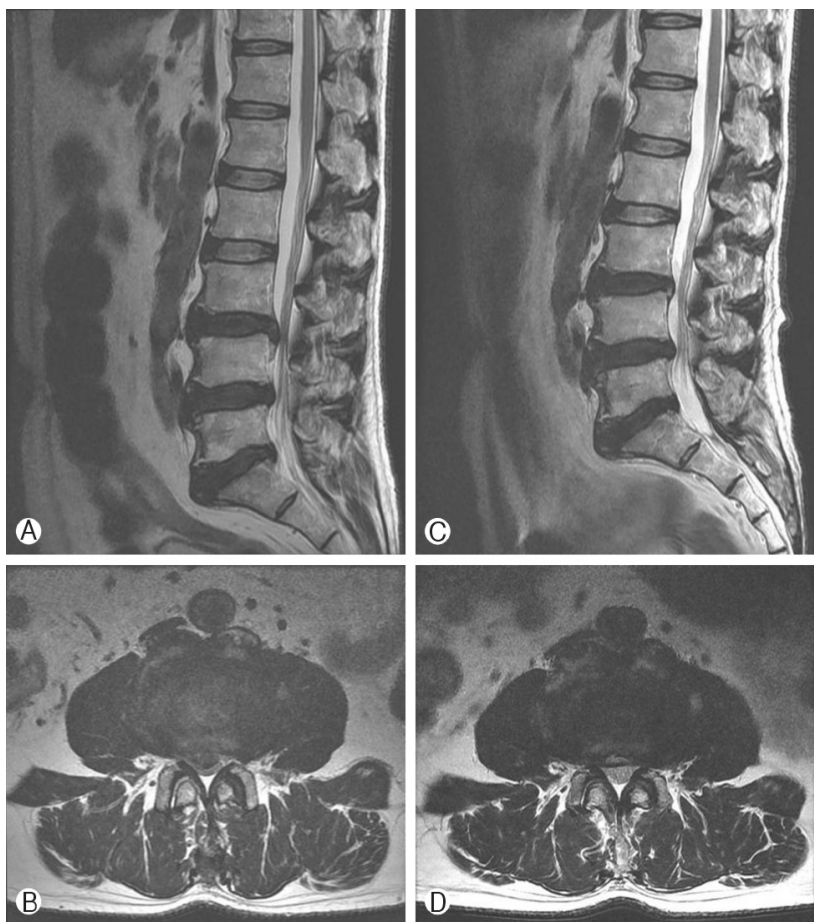

Fig. 1. Lumbar MR Images show central to right extrusion and downward migrated HNP at the L 3-4. Sagittal image A, axial image B. 3 months later, follow-up MR images shows marked decrease of HNP. Sagittal image C, axial image D.
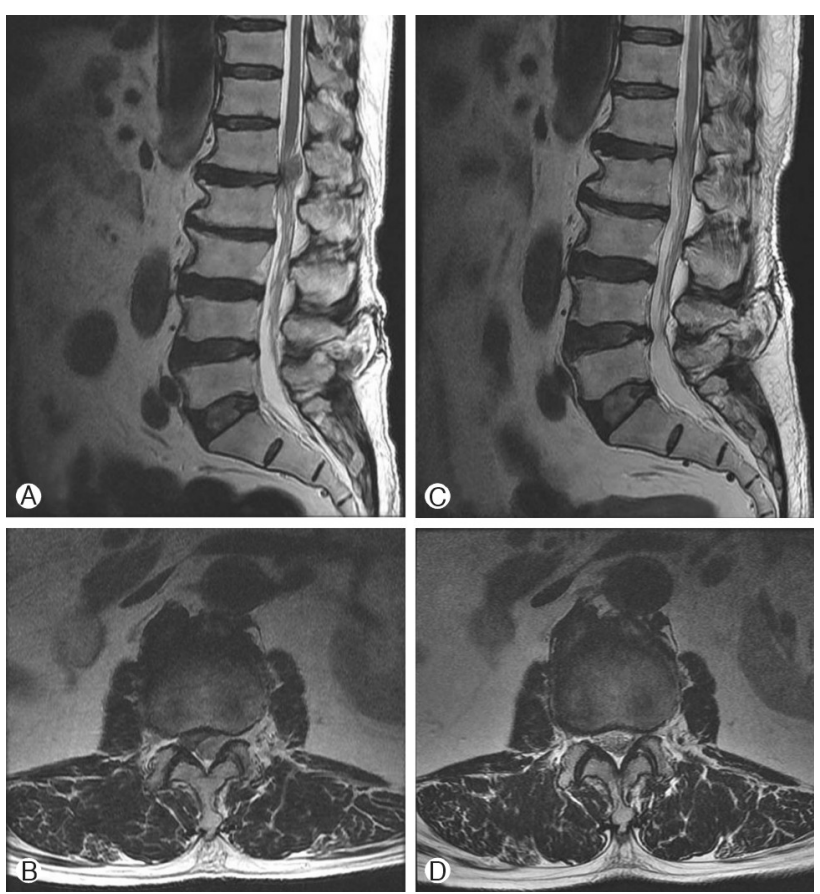

Fig. 2. Lumbar MR Images show right disc extrusion at the $L$ 1-2. Sagittal image A, axial image B. 3 months later, follow-up lumbar MR images shows no extruded HNP. Sagittal image C, axial image D.
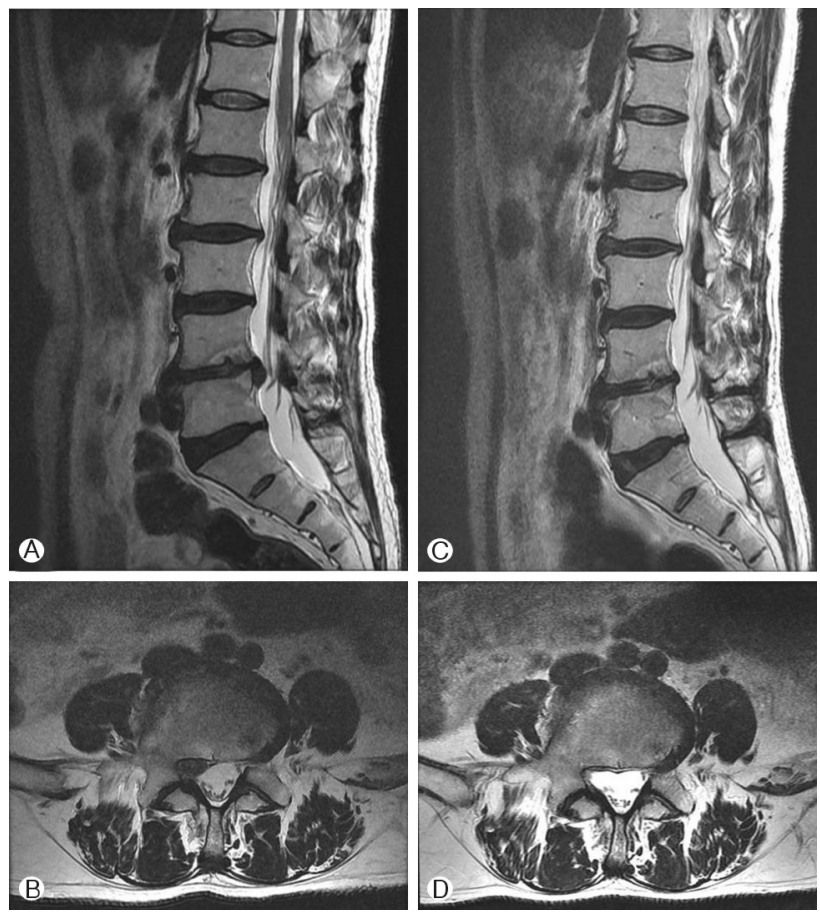

Fig. 3. Lumbar MR Images show right subarticular disc extrusion and downward migration at the L 4-5. Sagittal image A, axial image B. 9 months later, follow-up lumbar MR images shows no extruded and migrated HNP. Sagittal image C, axial image D.

\section{Case 3}

A 67-year-old male was admitted to our hospital with right lower extremity pain and hypoesthesia, especially on the left L5 dermatome. MR images showed extruded HNP at the L 4-5 level (Fig. 3A, B). We recommended surgical treatment, but he refused. As such, we treated conservatively. The pain was relieved gradually and followed up as an outpatient. Nine months later, the pain disappeared and the hypoesthesia was weakly remained. Follow-up MR images showed no HNP (Fig. 3C, D).

\section{DISCUSSION}

HNP is one of the most common diseases that induce radicular pain and back pain. Spontaneous regression of HNP correlates with clinical improvement and is confirmed by serial MR images. The mechanism of spontaneous regression may be retraction, dehydration/degradation and inflammatory reaction with neovascularization. A correlation between the macrophage tissue infiltration and the symptom is not clear ${ }^{11}$. Morphological changes on MRI mainly correspond to clinical outcomes $^{8)}$. 
The type of disc herniation is more contributable to spontaneous disc regression than the size of disc herniation. Transligamentous extension type of herniated disc material is more favorable than subligamentous and sequestrated type herniation $^{1)}$. In another study ${ }^{8}$, disappearance of HNP was seen frequently in the cases of migrating disc herniation, and it was presumed that the disc is more exposed to the epidural vascular supply. In case of extrusion or sequestration, an autoimmune response is promptly activated ${ }^{16}$.

Neovascularization in the outermost areas of HNP, presenting an enhancing rim in MR images, is thought to be a major determinant of spontaneous regression of $\mathrm{HNP}^{2}$. At MR image, the hypervascularization is easily detected by contrast enhancement. However, the degree of neovascularization is varied. Newly developed vessels in and surrounding HNP play an important role in the wound healing process and resorption of HNP. Epidural application of basic fibroblast growth factor (bFGF) accelerated the process of resorption ${ }^{9}$. Neovascularization was observed at the periphery of the sequestrated discs. Many foamy cells (macrophages) were present in the vascularized areas ${ }^{5)}$. Enhanced lesion at periphery of herniated disc is considered to represent inflammatory granulation. Inflammatory cells are most commonly seen in the sequestrated type $\mathrm{HNP}^{17}$. There was prominent infiltration of the inflammatory cells in the periphery of the extruded or sequestrated discs and most of them are macrophages. Macrophages are observed only in the periphery of the disc fragments ${ }^{4}$. Tumor necrosis factor (TNF)-a was the initiator of the inflammation, following contact between the macrophages and disc tissue. TNF-a could also act to accelerate the cascade of both angiogenesis and matrix degradation ${ }^{6}$.

Thickness of rim enhancement is a more important factor to spontaneous regression than the extent of rim enhancement ${ }^{2}$. When rim enhancement is present on enhanced MR images, there is a possibility of spontaneous regression even though the herniated mass may be located within the intradural space ${ }^{14)}$. The ratio of reduction in size of enhancing lesions is even higher in T2 hyperintense herniations ${ }^{16}$. The relatively-high water content can be the expression of soft, well-hydrated disc material or even an edema related to neovascularization and inflammatory reaction ${ }^{16}$. MR images are considered as a useful tool to predict the spontaneous regressive potential of HNP. Also, CT scan and MR images are the best diagnostic method to identify the spontaneous regression of HNP.

Spontaneous regression of disc is seen occasionally ${ }^{10,12,13,15)}$. Therefore, non-surgical treatment can be an another therapeutic option to treat HNP, when the patients did not want surgical treatment or if there is no neurological deficit ${ }^{12,13,14)}$. Our three patients were also recovered conservatively.

\section{CONCLUSION}

Spontaneous regression of HNP is rare condition, but conservative treatment may be another option if the patient did not have motor weakness and bladder symptom, even though the size of herniated disc is large.

\section{REFERENCES}

1. Ahn SH, Ahn MW, Byun WM: Effect of the transligamentous extension of lumbar disc herniations on their regression and the clinical outcome of sciatica. Spine (Phila Pa 1976) 25(4):475-480, 2000

2. Autio RA, Karppinen J, Niinimaki J, Ojala R, Kurunlahti M, Haapea $\mathrm{M}$, et al: Determinants of spontaneous resorption of intervertebral disc herniations. Spine (Phila Pa 1976) 31(11):12471252, 2006

3. Borota L, Jonasson P, Agolli A: Spontaneous resorption of intradural lumbar disc fragments. Spine J 8:397-403, 2008

4. Ikeda T, Nakamura T, Kikuchi T, Umeda S, Senda H, Takagi $\mathrm{K}$ : Pathomechanism of spontaneous regression of the herniated lumbar disc: histologic and immunohistochemical study. J Spinal Disord 9(2):136-140, 1996

5. Ito T, Yamada M, Ikuta F, Fukuda T, Hoshi SI, Kawaji Y, et al: Histologic evidence of absorption of sequestration-type herniated disc. Spine (Phila Pa 1976) 21(2):230-234, 1996

6. Kato T, Haro H, Komori H, Shinomiya K: Sequential dynamics of inflammatory cytokine, angiogenesis inducing factor and matrix degrading enzymes during spontaneous resorption of the herniated disc. J Orthop Res 22:895-900, 2004

7. Kil JS, Eom KS, Park JT, Moon SK, Kim TY: Spontaneous regression of lumbar herniated intervertebral disc. Kor J Spine 7(1):34-36, 2010

8. Komori H, Shinomiya K, Nakai O, Yamaura I, Takeda S, Furuya $\mathrm{K}$ : The natural history of herniated nucleus pulposus with radiculopathy. Spine (Phila Pa 1976) 21(2):225-229, 1996

9. Minamide A, Hashizume H, Yoshida M, Kawakami M, Hayashi N, Tamaki T: Effects of basic fibroblast growth factor on spontaneous resorption of herniated intervertebral discs. Spine (Phila Pa 1976) 24(10):940-945, 1999

10. Reyentovich A, Abdu WA: Multiple independent, sequential, and spontaneously resolving lumbar intervertebral disc herniations. Spine (Phila Pa 1976) 27(5):549-553, 2002

11. Rothoerl R, Woertgen C, Holzschuh M, Brehme K, Ruschoff J, Brawanski A: Macrophage tissue infiltration, clinical symptoms, and signs in patients with lumbar disc herniation. Aclinicopathological study on 179 patients. Acta Neurochir (Wien) 140: 1245-1248, 1998

12. Ryu SJ, Kim IS: Spontaneous regression of a large lumbar disc extrusion. J Korean Neurosurg Soc 48:285-287, 2010

13. Sabuncuoglu H, Ozdogan S, Timurkaynak E: Spontaneous regression of extruded lumbar disc herniation: report of two illustrative case and review of the literature. Turk Neurosurg 18(4): 392-396, 2008 
14. Sakai T, Tsuji T, Asazuma T, Yato T, Matsubara O, Nemoto K: Spontaneous resorption in recurrent intradural lumbar disc herniation. J Neurosurg Spine 6:574-578, 2007

15. Slavin KV, Raja A, Thornton J, Wagner FC Jr.: Spontaneous regression of a large lumbar disc herniation: report of an illustrative case. Surg Neurol 56(5):333-336, 2001

16. Splendiani A, Puglielli E, De Amicis R, Barile A, Masciocchi C,
Gallucci M: Spontaneous resolution of lumbar disk herniation: predictive signs for prognostic evaluation. Neuroradiology 46: 916-922, 2004

17. Virri J, Gronblad M, Seitsalo S, Habtemariam A, Kaapa E, Karaharju E: Comparison of the prevalence of inflammatory cells in subtypes of disc herniations and associations with straight leg raising. Spine (Phila Pa 1976) 26(21):2311-2315, 2001 